\title{
From the Editor
}

The focus of this journal is on an exchange of perspectives. The typical issue contains two focal articles, which summarize a body of conceptual and/or empirical literature on a topic of broad interest and offer a point of view about that body of work. Each focal article is followed by a set of commentaries, reflecting research, practice, and international perspectives on the issues raised in the focal article. These commentaries are followed by an integrative response from the author(s) of the focal article. (See www.siop.org/journal/siopjournal.aspx for details about the journal.)

The first focal article in this issue is by Douglas McKenna and Sandra Davis, titled "Hidden in Plain Sight: The Active Ingredients of Executive Coaching." They make the case that research on the determinants of the effectiveness of psychotherapy offers a deep understanding of how people change and how to help them do so, and they make linkages between that body of research and the domain of executive coaching. Their article is followed by nine commentaries that offer a variety of perspectives on executive coaching. These are followed by an integrative response from McKenna and Davis.

The second, by Ronald Bledow, Michael Frese, Neil Anderson, Miriam Erez, and James Farr, is titled "A Dialectic Perspective on Innovation: Conflicting Demands, Multiple Pathways, and Ambidexterity." The authors offer a novel perspective on the management of innovation. Their article is followed by six commentaries and an integrated response from Bledow et al.

For each focal article, a project team was assembled to review commentary submissions. For the focal article on executive coaching, the team was made up of Robert Lee, David Peterson, and Anna Marie Valerio. For the article on innovation, the team was made up of Samuel Hunter, Christina Shalley, and Susan Taylor. They deserve thanks for their contributions to this issue.

Paul R. Sackett University of Minnesota 